\title{
El privilegio de inembargabilidad ante el Tribunal Constitucional (un comentario a la STC 166/1998, de 15 de julio)
}

\author{
José Luis Carro Fernández-Valmayor \\ Catedrático de Derecho Administrativo \\ Universidad de Santiago de Compostela
}

Sumario: I. UNA REFERENCIA A LA JURISPRUDENCIA CONSTITUCIONAL PRECEDENTE. II. UNA ALUSIÓN A LAS POSICIONES DOCTRINALES. III. UNA EXPLICACIÓN HISTÓRICA. IV. LA DOCTRINA DE LA STC 166/1998.

\section{UNA REFERENCIA A LA JURISPRUDENCIA CONSTITUCIONAL PRECEDENTE}

En la recientísima Sentencia 166/1998, de 15 de julio, nuestro Tribunal Constitucional ha tenido, al fin, a través del planteamiento de una cuestión de inconstitucionalidad, la posibilidad de enfrentarse directamente con el tradicional privilegio administrativo de la inembargabilidad de los bienes públicos. En fechas inmediatamente posteriores acaban de aparecer las STC 201/1998, de 14 de octubre, 209/1998, 210/1998, $211 / 1998$, todas ellas del 27 de octubre, y la 228/1998, de 1 de diciembre, que ya siguen la doctrina sentada en la Sentencia 166/1998.

Lo cierto es que la doctrina contenida en esta importante Sentencia 166/1998 es tributaria de la que el Alto Tribunal ha ido paulatinamente desarrollando, en materia de ejecución de sentencias, a partir de su primera jurisprudencia, sin que podamos todavía considerar que nos hallamos en un punto de llegada definitivo en temática tan decisiva como ésta para el Estado de Derecho.

Ya en su temprana Sentencia 32/1982, de 7 de junio, nuestro Tribunal Constitucional tuvo ocasión de introducir una matización importante a la hora de determinar el papel del principio de legalidad presupuestaria en la ejecución de sentencias de condena a la Administración al pago de una cantidad de dinero. Se daría en este supuesto, según el Alto Tribunal, una situación de tensión entre dos principios constitucionales: el de seguridad jurídica, que obliga al cumplimiento de las sentencias judiciales, y el de legalidad presupuestaria, que supedita dicho cumplimiento a la existencia de la correspondiente partida presupuestaria asignada a tal fin. Pues bien, 
en la citada Sentencia $32 / 1982^{~}$ se va a afirmar que dicha tensión exige la armonización de ambos principios, aunque se añade inmediatamente que dicha armonización, cualquiera que sea la forma en que se realice,

«no puede dar lugar a que el principio de legalidad presupuestaria deje de hecho sin contenido un derecho que la Constitución reconoce y garantiza, pues, como hemos señalado anteriormente, el cumplimiento de las sentencias forma parte del derecho a la tutela efectiva de los Jueces y Tribunales consagrado en el artículo 24 » (F.J. 3. ${ }^{\circ}$ ).

Otra importante matización ulterior fue añadida por el Tribunal en su Sentencia 61/1984, de 16 de mayo, al afirmar que

«cuando en un litigio el condenado es el Estado, bajo una u otra personalidad, y la condena es de carácter pecuniario, el pago no puede hacerse sin dar cumplimiento a los requisitos exigidos por las normas legales que regulan las finanzas públicas, entre las que debe destacarse el artículo 44 de la Ley General Presupuestaria...» (F.J. 3..$^{\circ}$.

Y recuérdese que en la norma del citado artículo 44 se consagraban los privilegios administrativos de inembargabilidad y autoejecución, limitando la obligación de pago de las Administraciones a los límites del respectivo presupuesto, sin perjuicio de la solicitud a las Cortes Generales, dentro de los tres meses desde la notificación de la resolución judicial, de un crédito extraordinario o un suplemento de crédito ${ }^{2}$.

Era evidente, pues, que esta doctrina jurisprudencial colocaba a la Administración pública en una posición totalmente distinta a la del deudor privado; posición que, lejos de constituir, como parece, un indudable privilegio, se consideraba en la Sentencia 206/1993, de 22 de junio, como una «minusvalía» de la Administración derivada de los principios de legalidad y de contabilidad pública, a los cuales se encuentra sometida constitucionalmente y que, siempre según esta Sentencia, condicionan su actuación y obstaculizan la agilidad de movimientos muy por bajo del nivel de los particulares en el ejercicio de su libertad. Esto hace que, conse-

\footnotetext{
1 Rodriguez Berejuo consideró a esta Sentencia como el leading case en materia de ejecución de las sentencias de condena a la Administración al pago de una suma de dinero. «Jurisprudencia constitucional y Derecho presupuestario. Cuestiones resueltas y temas pendientes», REDC, 15, 1995, págs. 9 y ss., en concreto pág. 34 .

2 Precisamente en la citada Sentencia 61/1984 se desestimaba el recurso de amparo por la razón de que la Administración pública había llevado a cabo las actividades necesarias a fin de que los correspondientes créditos para el cumplimiento de la sentencia fuesen consignados en los Presupuestos del Estado. Por ello el Tribunal no advertía en la Administración una conducta pasiva u obstaculizadora del cumplimiento de la resolución judicial con lesión de los derechos de los recurrentes (F.J. 4. ${ }^{\circ}$ ).
} 
cuentemente, en la citada Sentencia se pueda afirmar que la resolución judicial firme no se convierte

«en un título directamente ejecutable, equivalente a una orden de pago, desde el momento en que los Jueces y Tribunales no podrán despachar mandamiento de ejecución ni dictar providencias de embargo contra los derechos, fondos, valores y bienes en general de la Hacienda pública y ha de encauzarse a través de un complejo procedimiento administrativo de ejecución del gasto que en más de un caso necesita una prolongación parlamentaria (arts. 44 y 64 LGP)» (F.J. $\left.4 .^{\circ}\right)^{3}$.

En esta línea justificativa de la especial posición de la Administración pública, el Tribunal Constitucional ha subrayado que, al ser el derecho de tutela judicial efectiva un derecho de configuración legal, el legislador puede establecer límites a la ejecución de sentencias, siempre que los mismos sean razonables y proporcionales respecto de los fines que lícitamente puede aquél perseguir en el marco de la Constitución. Y así nos dice en su Sentencia 107/1992, de 1 de julio, que

«debe reputarse legítimo desde el punto de vista constitucional que el Legislador, con un fundamento objetivo y razonable, impida que la potestad de ejecución forzosa pueda dirigirse sobre determinados bienes» (F.J. 3..$^{\circ}$ ).

\section{Y, a modo de explicación, añade a continuación que}

«los principios de legalidad presupuestaria y de continuidad de los servicios.públicos, entre otros, sirven de fundamento a la exclusión de la ejecución forzosa respecto de bienes de titularidad pública» (F.J. 3..).

Como se puede comprobar, esta doctrina jurisprudencial, que he resumido mínimamente hasta aquí, ha intentado encontrar por distintas vías una justificación, o si se quiere, una explicación fundamentada a ese importante límite al derecho consagrado en el artículo 24 de la Constitución constituido por los distintos supuestos de inembargabilidad. De esta justificación o explicación partirá, como veremos, la Sentencia 166/1998 cuando afronte directamente el problema. Antes de entrar en su análisis quisiera, sin embargo, hacer alguna alusión a las posturas doctrinales anteriores a la misma que nos puedan servir para conocer en qué ambiente teórico se produce la decisión del Tribunal Constitucional.

\footnotetext{
${ }^{3}$ Cfr., en todo caso, los fundamentados, y para mi convincentes, votos particulares formulados a la Sentencia por A. Rodríguez Bereijo, al que se adhiere F. García-Mon y González Regueral, y J. V. Gimeno Sendra, al que se adhiere C. de la Vega Benayas.
} 


\section{UNA ALUSIÓN A LAS POSICIONES DOCTRINALES}

La doctrina, en efecto, se había venido preocupando desde hacía algún tiempo por determinar el alcance y justificación de este importante privilegium fisci, que afecta de forma tan determinante al principio de ejecución judicial de las sentencias condenatorias de la Administración y, en general, al mismo régimen jurídico de los bienes públicos.

En una línea crítica sobre el significado y alcance del privilegio administrativo de inembargabilidad ha sido el profesor GARCÍA de ENTERRÍA el que ha aportado los argumentos más contundentes ${ }^{4}$. Después de constatar que este privilegio ha marcado durante siglos el régimen de ejecución de condenas al pago de cantidad por la Administración y ha encontrado, como tendremos ocasión de comprobar, permanente acogida en nuestro Derecho positivo, afirma que, hoy en día, nos hallamos ante una clara situación de inconstitucionalidad. Y ello en base a cuatro motivos principales ${ }^{5}$ :

Primero. Esta situación es incompatible con el marco de economía de mercado impuesto para la actividad empresarial por el artículo 38 de la Constitución. No puede haber vinculación de los contratos, y en general de las obligaciones patrimoniales derivadas de otros títulos, sin la posibilidad de ejecución forzosa de las prestaciones incumplidas.

Segundo. Esta situación atenta directamente contra el principio constitucional de igualdad (artículo 14 de la Constitución) en la medida en que se prevé la ejecución forzosa de un crédito en las relaciones entre entes públicos (en los procedimientos de retención o compensación) ${ }^{6} \mathrm{y}$ se impide en las relaciones de éstos con los particulares.

Tercero. Esta situación es contraria a los artículos $24,106,117-3 .^{\circ}$ y 118 de la Constitución y excede claramente del único supuesto de inembargabilidad previsto por la misma en su artículo $132-1 .^{\circ}$.

\footnotetext{
${ }^{4}$ Vid., «Sobre el principio de inembargabilidad, sus derogaciones y sus límites constitucionales y sobre la ejecución de sentencias condenatorias de la Administracióny, REDA, 52, 1986, págs. 485-588. Hacia una nueva justicia administrativa, 2. ${ }^{a}$ ed., Civitas, Madrid, 1992, donde se incluye el trabajo anteriormente citado (págs. 105-148); vid., además, págs. 72-73, 154-155, y el trabajo «La transformación del contencioso-administrativo francés: la reforma radical del sistema de ejecución de sentencias", en págs. 201 y ss. Curso de Derecho administrativo, tomo II, 5. ${ }^{a}$ ed., Civitas, Madrid, 1998, págs. 643 y ss.

5 Vid., «Sobre el principio de inembargabilidad», cit., págs 495-497 (cito por las págs. de la REDA).

${ }^{6}$ Cfr., últimamente, la Disposición Adicional 26. ${ }^{a}$ de la reciente Ley 50/1998, de 30 de diciembre, de Medidas Fiscales, Administrativas y del Orden Social.
} 
Cuarto. Esta situación es incompatible también con el principio de la responsabilidad de los poderes públicos consagrado en el artículo 9-3..$^{\circ}$ del texto constitucional.

En línea con estos argumentos, y a la hora de abordar la problemática de la ejecución de las sentencias condenatorias de la Administración, una parte importante de la doctrina ha ido poniendo en cuestión la admisibilidad general del privilegium fisci de la inembargabilidad ${ }^{7}$. Posición crítica a la que se ha adherido la doctrina procesalista, en donde también se ha afirmado la incompatibilidad de tal privilegio con el texto constitucio nal ${ }^{8}$.

Un tema que ha suscitado especial atención ha sido el de la posibilidad de que la ejecución forzosa se dirigiera contra el dinero público. Se trataría de supuestos en que la ausencia de previsión presupuestaria expresa no permitiría la ejecución de las sentencias firmes de condena a la Administración al pago de cantidad líquida. Ha de decirse que, desde el punto de vista del principio de legalidad presupuestaria, la cuestión tendría dificil solución; de ahí que se intentasen buscar distintas soluciones con vistas a solventar este problema. Se propuso así la inclusión en los Presu-

${ }^{7}$ Cfr. los trabajos citados por Ballesteros MofFa, «La doctrina del Tribunal Constitucional sobre el privilegio de inembargabilidad de los bienes y fondos públicos», en Sentencias de Tribunales Superiores de Justicia y Audiencias Provinciales y otros Tribunales, $\mathrm{n}^{\circ}{ }^{\circ}$ 10, octubre, 1998, en pág. 10, nota 1. Morillo Velarde, comentando la Sentencia constitucional 67/1984, de 7 de junio, concluía con la inconstitucionalidad de los preceptos sobre inembargabilidad. « $i s$ procedente el embargo de los bienes de la Administración en ejecución forzosa de sentencia condenatoria recaída en recurso contencioso-administrativo?», REDA, 43, 1984, págs. 585-591. Vid. igualmente, RUiz OJEDA, La ejecución de créditos pecuniarios contra entes públicos, Civitas-Universidad de Málaga, Madrid, 1993, págs. 29-40; para este autor, la norma constitucional fundamental de la que debe partirse en esta temática es la de la responsabilidad de los poderes públicos del artículo $9-3 .^{\circ}$ de la Constitución (pág. 40). Vid. también, LóPEZ GONZÁLEZ, «El sistema español de ejecución de sentencias condenatorias de la Administración», en La justicia administrativa en el Derecho comparado (Coord. J. Barnes), Civitas-Consejería de la Presidencia de la Junta de Andalucía, Madrid, 1993, pág. 442: «La ejecución forzosa por los tribunales para el pago de dinero por la Administración no perturba ningún servicio público».

8 Vid. GutiérRez de CABIEDes, «Inejecución por la Administración Pública de condenas pecuniarias acordadas en sentencia firme judicial", en Libro Homenaje a Jaime Guasp. Comares, Granada, págs. 303 y ss., en concreto págs. 311-313. También, GIMENo SENDRA, «Alternativas a la disfuncionalidad del procedimiento de ejecución de sentencias contencioso-administrativas», REDA, 27, 1980, págs. 563 y ss., en concreto págs. 575-576, que utiliza como referencia la Ley alemana de la Jurisdicción contencioso-administrativa $(V w G O)$. ARMENTA DEU, «Consideraciones sobre inembargabilidad por motivos de Derecho público y ejecución de sentencias condenatorias de la Administración», Revista de Derecho Procesal, 1, 1989, págs.7 y ss., que, reconociendo la dificultad constituida por la existencia de preceptos que prohíben el embargo de determinados bienes de la Administración, afirma que, lege ferenda, la inembargabilidad debería limitarse únicamente a los bienes o derechos afectos al funcionamiento de los servicios públicos (págs. 42-45, en concreto pág. 43). 
puestos Generales del Estado de cada año de un crédito que tuviese la condición de ampliable ${ }^{9}$, la consignación de una partida presupuestaria a disposición de los Tribunales vinculada a la ejecución de las sentencias ${ }^{10}$ o, más generalmente, la consideración de la sentencia judicial firme como un supuesto de generación del correspondiente crédito presupuestario ${ }^{11}$.

A pesar de lo imaginativo de estas soluciones, la cuestión de fondo, esto es, la posibilidad de la embargabilidad general del dinero público, con independencia de la existencia de concreto crédito presupuestario para atender a la obligación, permanecía imprejuzgada. Contra la admisión de tal posibilidad se podría esgrimir, sin embargo, el mismo principio de legalidad presupuestaria en su versión de vinculación o afectación del dinero público a las finalidades previamente determinadas en la Ley de Presupuestos.

Frente a ello afirmaba GARCÍA DE ENTTERRÍA que, dentro de la tutela judicial efectiva y de la facultad de los Jueces y Tribunales de hacer ejecutar lo juzgado, debería necesariamente incluirse el poder de dictar mandamientos ejecutivos de pago contra la Hacienda, esto es, contra la cuenta del Tesoro Público del Banco de España, sin que el argumento de la inexistencia de crédito presupuestario en el caso de condenas a pago de cantidad líquida apareciese como consistente. Por lo demás, de manera muy oportuna, hacía observar nuestro autor que de la ejecución de dinero público no tiene por qué derivarse perjuicio alguno para los servicios públicos, ya que, precisamente, no puede hablarse de perjuicio cuando la Administración deja de disponer de un dinero que no le corresponde retener. El dinero administrativo, dado su carácter de valor económico universal y abstracto, no es; de otro lado, como también nos señala GARCíA DE ENTERRÍA, un bien de dominio público en el sentido del artículo $132-1 .^{\circ}$ de la Constitución a los efectos de extenderle el privilegio de la inembargabilidad ${ }^{12}$.

\footnotetext{
${ }^{9}$ Rodríguez BereiJo, cit., pág. 36. Cfr. igualmente el voto particular que este autor, en su calidad de magistrado constitucional, formuló a la STC 206/1993, de 22 de junio.

10 González Pérez, Comentarios a la Ley de la Jurisdicción contencioso-administrativa, tomo II, 3. ${ }^{\text {e }}$ ed., Civitas, Madrid, 1998, pág. 1822.

1 AlbiÑana Garcta-Quintana, «¿Las sentencias judiciales engendran créditos presupuestarios?», Presupuesto y Gasto Público, 2, 1979, págs. 49 y ss., en especial págs. 49-50 y 53-54. Cfr. el voto particular de Rodríguez Bereijo a la STC 206/1993, cit.

12 GarCla de ENTERRIA, «Sobre el principio de inembargabilidad», cit., págs. 504-505; Hacia una nueva justicia administrativa, cit., pág. 160; «Los postulados constitucionales de la ejecución de las sentencias contencioso-administrativas», Documentación Administrativa, 209, 1987, pág. 14. Vid.
} 
Esta posición de GARCÍA DE ENTERRÍA sobre la posibilidad de la ejecución forzosa del dinero administrativo ha sido aceptada por una parte importante de la doctrina. Incluso algún autor, como RUIZ OJEDA, ha llegado a afirmar que «sostener que el dinero público es inejecutable por estar vinculado o afectado por la Ley del Presupuesto cuando la Administración está ampliamente facultada para sortear tal vinculación es algo que sólo puede ser calificado de bochornoso"» ${ }^{13}$.

La embargabilidad del dinero público ha sido admitida, por lo demás, en algunos Ordenamientos extranjeros. Como ejemplo puede traerse a estas páginas una interesante Sentencia de la Corte Constitucional italiana de 21 de julio de 1881, n. $138^{14}$, en donde se afirmó que, no teniendo la Administración una posición distinta a la de cualquier otro deudor ante las sentencias de condena al pago de una suma, «el no sometimiento a la ejecución forzosa de las sumas de dinero o de los créditos pecuniarios del Estado y de los Entes públicos solamente puede derivarse del hecho de que aquéllos concurran a formar el patrimonio indisponible ${ }^{15}$, esto es, como se ha visto, del hecho de que aquéllos estén vinculados a un servicio público o, como por ejemplo los créditos tributarios, nazcan del ejercicio de una potestad pública». Con todo -añade la Corte Constitucional italiana- el dinero y los créditos pecuniarios, «por la naturaleza fungible e instrumental del dinero mismo, dificilmente pueden considerarse sujetos a vínculos de destino, a no ser que estén destinados de forma inmediata, en su individualidad, a un fin público».

también, BELTRÁN DE FELIPE, El poder de sustitución de las sentencias condenatorias de la Administración, Civitas-Ministerio de Justicia e Interior, Madrid, 1995, págs. 333-334, que añade el matiz de que «los caudales y fondos de las Administraciones pueden tener un destino concreto (incluso a veces determinado por ley) que tal vez no sea susceptible de verse alterado por una sentencia».

- ${ }^{13}$ RUIz OJEDA, La ejecución de créditos pecuniarios contra entes públicos, cit., pág. 249. Más adelante subraya que «la admisión de la ejecución forzosa de dinero público en base a un título ejecutivo válidamente configurado es la salida única y necesaria. $Y$ ello con independencia de que exista $o$ no crédito presupuestario para atender a la obligación. Se trata, en definitiva, de hacer lo que la propia Administración puede hacer por si y no hace: pagar primero y realizar posteriormente las operaciones de ajuste" (pág. 250). Por cierto, este mismo autor observa, con acertados argumentos, que la no existencia de crédito presupuestario no puede transformar lo que es una responsabilidad contractual en una responsabilidad aquiliana o extracontractual (págs. 242-248). Vid. también BeLTRÁN DE FeliPE, op. et loc. cit. Cano Mata, «Ejecución judicial de sentencias contencioso-administrativas. El embargo a la Administración como manifestación del principio de tutela judicial efectiva», $R A P, 103,1984$, págs. $42-45$.

${ }^{14}$ Giurisprudenza Costituzionale, parte prima, 1981, págs. 1326-1338. En nuestro pais esta Sentencia ha sido comentada por C. CHINCHILLA, «La ejecución de sentencias en el Derecho italiano: il giudizio di ottemperanza", REDA, 59, 1988, págs. 438-439.

${ }^{15}$ En el Ordenamiento italiano los bienes públicos se clasifican en tres categorías: demaniales, patrimonio indisponible y patrimonio disponible (articulos 826 y 828 del Código Civil italiano). Por todos, vid. CHINCHILLA, cit. pág. 438. 
Como ha sido ya observado entre nosotros ${ }^{16}$, en el Derecho alemán (arts. 170 de la Ley de la Jurisdicción contencioso-administrativa de 25 de mayo de 1976, $V w G O$, y 882a de la Ley de Enjuiciamiento Civil de 30 de enero de $1877, Z P O$, con múltiples modificaciones posteriores) se parte de la regla general de que los bienes de la Hacienda Pública pueden ser objeto de embargo, aunque se excepcionan los bienes que sean indispensables para la realización de las tareas o funciones públicas o los bienes cuya ejecución contradiga un interés público. Es necesario resaltar, además, el dato significativo que sobre la posibilidad misma del embargo decide el propio Tribunal (arts. $170-3 .{ }^{\circ} \mathrm{VwGO}$ y $882 \mathrm{a}-2 . .^{\circ} \mathrm{ZPO}$ ).

En esta apresurada panorámica doctrinal no puede dejar de aludirse, por último, a una serie de autores que, desde una perspectiva distinta, han puesto el acento en la función que le toca cumplir al principio de inembargabilidad de bienes y fondos públicos, intentando una justificación o explicación de su existencia. Así, FONT I LLOVET ha resaltado, en esta temática, la función de garantía que cumple el principio de legalidad presupuestaria de la que se derivarían las limitaciones que provocan el incumplimiento de las sentencias condenatorias. La vinculación de la Administración a tal principio es, para este autor, en realidad, una «prerrogativa en menos», según la conocida terminología acuñada por RIVERO. Reconoce nuestro autor que dicho principio de legalidad presupuestaria ha de ser armonizado, en el sentido de la ya citada jurisprudencia constitucional, con el de seguridad jurídica y que dicha armonización no puede jamás realizarse con lesión de un derecho fundamental como es el de la ejecución de sentencias. En todo caso para FONT no existiría tal lesión si la Administración se preocupase, a través de la correspondiente tramitación de un crédito, suplemento de crédito o crédito extraordinario, de obtener los fondos necesarios para hacer frente al cumplimiento de la sentencia. Lo que queda excluido en el pensamiento de FONT es la posibilidad mis-

\footnotetext{
16 Gimeno Sendra, cit., págs. 575-576. También, González-Varas IbáṄez, La Jurisdicción contencioso-administrativa en Alemania, Civitas-Ministerio de Justicia, Madrid, 1993, págs. 314-318. En el Derecho francés la Ley de 11 de julio de 1980 estableció un sistema de multas coercitivas (astreintes) contra la Administración para forzar el cumplimiento de las sentencias. En nuestro caso es interesante señalar que la Ley francesa determinó unos plazos dentro de los cuales debia hacerse efectivo el pago de las cantidades resultantes de las sentencias condenatorias de la Administración; en su defecto, se ordenaba al pagador competente que procediese a dicho pago, a petición del deudor y mediante presentación de la decisión judicial. Cuando la Entidad condenada fuese una corporación local o un establecimiento público, una vez vencido el plazo establecido para el cumplimiento de la sentencia, es la autoridad de tutela la que procede a ordenar de oficio la realización del pago. Vid. un minucioso análisis de esta Ley en PAREjo ALFonso, «Los poderes de ejecución del Juez contencioso-administrativo: la Ley francesa de 16 de julio de $1980 », R E D A, 33$, 1982, págs. 223 y ss., en especial págs. 238 y ss. También GARCíA DE ENTERRIA, «Sobre el principio de inembargabilidad», cit., pág. 507.
} 
ma de la embargabilidad de los bienes y fondos públicos; éstos gozan de una especial protección porque se encuentran preordenados a un fin específico consistente en la satisfacción de un particular segmento del interés público al que se hallan adscritos. De esta forma, la regla de la inembargabilidad no se presenta como un mero privilegio administrativo, sino, y sobre todo, según nuestro autor, como una formidable garantía de la colectividad y de los intereses públicos a cuya satisfacción los bienes y los fondos públicos se hallan adscritos ${ }^{17}$. En definitiva, pues, el principio de vinculación presupuestaria de los fondos públicos aparecería como un obstáculo insuperable que impediría su embargabilidad. Frente a ello no es menester insistir más en los argumentos antes expuestos sobre la posibilidad de embargo de fondos públicos que me parecen bastante decisivos. BASSOLS COMA entendió asimismo perfectamente compatible el privilegio de inembargabilidad de fondos y bienes públicos con el monopolio jurisdiccional de ejecución de sentencias que la Ley Orgánica del Poder Judicial había consagrado, de acuerdo con el texto constitucional, en su artículo 2. Bien es verdad que este autor sometía tal compatibilidad a la concurrencia de dos requisitos, mejoramiento de las técnicas presupuestarias para hacer efectivo el pago y establecimiento de medidas coactivas frente a la Administración, que, en todo caso, no ponían en cuestión la existencia de aquel privilegio ${ }^{18}$. FERNÁNDEZ FONTECHA se inclinó también por la instrumentación de una serie de medidas coercitivas (p.e., multas pecuniarias), acompañadas, en su caso, de una sanción penal, que obligasen a la Administración al cumplimiento de las sentencias. Todo ello a la vez que rechazaba la posibilidad legal de que la judicatura pudiese, con base en la Constitución, dictar mandamientos de pago contra el Banco de España. Sin plantearse su posible inconstitucionalidad, afirmaba este autor que el artículo 44 de la Ley General Presupuestaria es absolutamente tajante en la prohibición en él contenida; si se admitiesen mandamientos judiciales de pago contra el Banco de España «se habría abier-

\footnotetext{
17 FONT I Llovet, La ejecución de las sentencias contencioso-administrativas, Civitas, Madrid, 1985, págs. 131-139. Afirma, por lo demás, con cita del articulo 132 de la Constitución, que «la regla de la inembargabilidad de los bienes públicos está en nuestro ordenamiento en buena medida constitucionalizada» (pág. 138). Hay que observar, sin embargo, que dicha norma constitucional se refiere, como es sabido, a los bienes de dominio público y a los comunales y, por tanto, no es susceptible de ser extendida a los fondos públicos y a otros tipos de bienes. Vid. también «Medidas para hacer efectiva la ejecución de sentencias", en La protección juridica del ciudadano, Estudios en homenaje al profesor J. González Pérez, tomo II, Civitas, Madrid, 1993, pág. 1179, donde afirma que «no puede dejarse exclusivamente a la iniciativa judicial el libramiento de mandamientos de pago»».

18 Bassols COMA, «La ejecución de sentencias condenatorias de la Administración pública en jurisdicciones distintas a la contencioso-administrativan, Libro Homenaje al profesor J. L. Villar Palasi, Civitas, Madrid, 1989, págs. 132-133. También publicado en Documentación Administrativa, 209,1987 , págs. 47 y ss., en concreto págs. $75-78$.
} 
to -escribe FERNÁNDEZ FONTECHA - un peligrosísimo portillo en el cual el primer paso serían los bienes dinerarios y el segundo paso probablemente los bienes no dinerarios del Estado, con lo cual la rotundidad del artículo 44 y del principio de inembargabilidad de los bienes públicos se habría volatilizado en aras de una tesis excesivamente favorable al predominio del principio de tutela judicial efectiva» ${ }^{19}$. También entre los tributaristas CAYÓN GALIARDO justificó igualmente la necesidad de la existencia del privilegio de inembargabilidad de los fondos públicos apelando a la continuidad en la prestación de los servicios públicos; no veía este autor contradicción con la obligación de la Administración de cumplir las decisiones de los Tribunales en la medida en que aquélla, en caso de imposibilidad jurídica o presupuestaria, estaba obligada a solicitar los créditos oportunos ${ }^{20}$.

Éste es, pues, descrito de manera muy esquemática, el ambiente doctrinal existente que va a acompañar la aparición de la importante Sentencia 166/1998, de 15 de julio, del Tribunal Constitucional, de la que estas líneas quieren, simplemente, dar urgente noticia.

\section{UNA EXPLICACIÓN HISTÓRICA}

Una de las características reseñables de la Sentencia 166/1998 es que en ella se contiene una interesante explicación histórica de la existencia del privilegio de inembargabilidad. En efecto, en su Fundamento Jurídico 3. ${ }^{\circ}$ se comienza por afirmar que, en lo que se refiere al origen histórico del privilegio, debe partirse necesariamente de la anómala situación presupuestaria de los Ayuntamientos en la primera mitad del pasado siglo. Y esta situación — se nos dice en el citado Fundamento Jurídico - se produjo por el

\footnotetext{
19 FeRnÁNDez Fontecha, «La inembargabilidad de los fondos públicos. Análisis del alcance y limitaciones de los artículos 44 de la Ley General Presupuestaria y 18 de la Ley de Patrimonio del Estado», en Gobierno y Administración en la Constitución, vol. I, Dirección General del Servicio Jurídico del Estado-Instituto de Estudios Fiscales, Madrid, 1988, págs. 549 y ss., en especial págs. 570 y ss. La cita del texto en pág. 574. Criticaba también este autor la propuesta de crear un crédito presupuestario concreto por considerarlo incompatible con el principio constitucional de la igualdad en la medida en que podría darse la eventualidad de que dicho crédito no pudiese hacer frente a todas las sentencias de condena de la Administración, «a no ser que se optara claramente por la, en cierto modo, disparatada tesis del crédito ampliable» (pág. 572).

${ }^{20}$ Cayón Galiardo, «Las obligaciones económicas del Estado en la Ley General Presupuestaria», Presupuesto y Gasto Público, 3, 1979, págs. 75-76. «Creemos, en conclusión —escribe este autor (pág. 76)-, que el privilegio de inembargabilidad de los fondos públicos tiene un fundamento técnico y político que justifica suficientemente su mantenimiento, pero que es preciso revisar en profundidad todas las posibilidades legales para que la Hacienda Pública cumpla, y lo haga en la forma y tiempo que debe, sus obligaciones".
} 
tránsito de una Hacienda patrimonial, basada en ingresos derivados de los bienes, a una Hacienda fiscal, dependiente esencialmente de los correspondientes tributos. El mal estado de las finanzas locales, agravado por una ausencia casi total de una mínima disciplina presupuestaria y contable, se vio afectado de manera muy negativa por el frecuente recurso de los particulares a la ejecución forzosa de sus créditos contra los Ayuntamientos reconocidos por sentencia firme. Aunque la Ley de organización y atribuciones de los Ayuntamientos de 8 de enero de 1845 intentó racionalizar la Hacienda municipal estableciendo la obligación de inclusión en el presupuesto, como gasto obligatorio, del pago de las deudas (artículo 93-8. : «el pago de deudas y réditos de censos»); una Real Orden de 21 del mismo mes y año ordenaba la suspensión inmediata de todo apremio y ejecución contra fondos municipales al mismo tiempo que recordaba, eso sí, a los Ayuntamientos la mencionada obligación de incluir las deudas en sus presupuestos. (Lo que se reiteró - según se nos indica en la Sentencia constitucional - en la Circular del Ministerio de la Gobernación de 19 de mayo de 1845 y en la Real Orden de 22 de septiembre del mismo año). Todas estas previsiones pasan al Real Decreto de 12 de marzo de 1847, en donde se vuelve a declarar que las deudas de los Ayuntamientos deben incluirse en sus presupuestos, impidiéndose así a los Tribunales despachar mandamientos de ejecución contra fondos municipales ${ }^{21}$.

No debió ser nada fácil la consolidación de esta normativa, pues en este período se plantean varias cuestiones de competencia contra ejecuciones despachadas por los jueces, todas ellas resueltas en favor de la Administración. Sin desconocer la competencia judicial para declarar la deuda, se determina, sin embargo, que su ejecución corresponde a la propia Administración. Como nos dice el propio Tribunal Constitucional en el citado Fundamento Jurídico, la jurisprudencia de la época obtuvo las oportunas consecuencias para nuestro tema. En efecto, se reconoce que «la legitimidad de la deuda de un particular contra un Ayuntamiento, si es cuestionada, ha de ser resuelta por los Juzgados y Tribunales, a quienes corresponde dictar fallos declaratorios del derecho de las partes. Pero se agrega, en contrapartida, que la Sentencia que aquéllos dicten no produce otro efecto que el de la inclusión de la deuda en el presupuesto municipal, a lo que no puede negarse la Administración (Reales Decretos-Sentencias

\footnotetext{
${ }^{21}$ Respecto de los fondos estatales, cfr. las Reales Órdenes de 28 de febrero de 1844 y 14 de junio de 1845, cit. por Bassols, cit., pág. 117. También en el trabajo de Santamaría Pastor, «Sobre el origen y evolución de la reclamación administrativa previa», $R A P, 77,1975$, pág, 93, nota $16 \mathrm{y}$ págs. 96 y ss. Según SanTAMaria, en la citada Real Orden de 28 de febrero de 1844 «se encuentra el origen próximo de la regla de inembargabilidad de los fondos públicos» (pág. 97, nota 22 y pág. 98).
} 
del Consejo Real de 4 de junio de 1846, 9 de julio de 1846 y 29 de julio de 1846)» 22 .

Ha señalado BASSOLS ${ }^{23}$ que el insuficiente rango normativo de las disposiciones citadas, inspiradas en claros motivos hacendísticos, no era el adecuado para consagrar un privilegio de tanta trascendencia que equivalía a sustraer a los Tribunales ordinarios su función propia, que era la de juzgar y hacer ejecutar lo juzgado. De aquí que en 1847 se presentase a las Cortes un Proyecto de Ley (Proyecto Santillán) sobre Administración y Contabilidad, en donde se establecía de forma definitiva el principio de inembargabilidad. Con todo, para la consolidación de tal principio o privilegio habrá que esperar —como también nos señala nuestro Tribunal Constitucional-a la Ley de 20 de febrero de 1850 , por la que se fijan las bases de la contabilidad general, provincial y municipal, cuyo artículo 9 , apartado primero, declaró que «ningún Tribunal podrá despachar mandamiento de ejecución, ni dictar providencias de embargo contra las rentas ó caudales del Estado" ${ }^{24}$. Con posterioridad el Decreto de 9 de julio de 1869 (artículo 4) recordó la vigencia del citado artículo 9, cuyo contenido fue reiterado por la Ley provisional de Administración y Contabilidad de la Hacienda de 25 de junio de 1870 (artículo 16) ${ }^{25}$ y de ésta pasó a la Ley

\footnotetext{
${ }^{22}$ Señala también el Tribunal Constitucional que todo ello «entrañaba una directa relación entre inembargabilidad de la Hacienda Pública y la llamada autotutela ejecutiva de las distintas Administraciones, puesto que si «no pueden los Jueces y Tribunales ordinarios exigir créditos por sí aplicando las formas del juicio ejecutivo, ni de otro modo alguno", como se declaró en la citada Resolución del Consejo Real de 4 de junio de 1846, la conseçuencia obligada era la atribución a las Administraciones Públicas de una competencia exclusiva para proceder a la ejecución de las resoluciones judiciales condenatorias de éstas». Vid. también SANTAMARja, cit., págs. 93-94 y nota 17 que cita varios Reales Decretos-Sentencias del 25 de mayo de 1846. Igualmente A. Niero, Estudios históricos sobre Administración y Derecho Administrativo, INAP, Madrid, 1986, págs., 225-226 que alude a las mencionadas Decisiones del Consejo Real de 1846. Por cierto que en el Considerando $1 .^{\circ}$ de la de 29 de julio se afirmaba «que si los jueces estuviesen facultados para exigir directamente por ejecución y apremio las deudas referidas, podrían introducir en la contabilidad comunal un desconcierto mayor o menor, borrar el presupuesto municipal, destruir en suma á nombre de la ley la obra de la misma».
}

${ }^{23}$ Op. cit., pág. 117.

${ }^{24}$ El apartado segundo del citado artículo 9 determinó, muy significativamente, que «los que fueren competentes para conocer sobre reclamación de créditos á cargo de la Hacienda pública y en favor de particulares, dictarán sus fallos declaratorios del derecho de las partes, y podrán mandar que se cumplan cuando hubieren causado ejecutoria; pero este cumplimiento tocará exclusivamente á los agentes de la administración, quienes con autorización del Gobierno acordarán y verificarán el pago en la forma y dentro de los límites que señalen las leyes de presupuestos y las reglas establecidas por el de las obligaciones del Estador. Vid. también los articulos 195 a 197 de la Ley de Ayuntamientos de 5 de julio de 1856, en donde, por cierto, se exceptuaba de la prohibición del procedimiento de apremio «las deudas que tengan constituidas á su favor prenda o hipoteca» (art. 196).

${ }^{25}$ El 16 de abril de 1881 se aprueba la conocida Real Orden referente a la compilación de las disposiciones vigentes en los diversos servicios que corren a cargo de la Dirección General de lo Conten- 
de 1 de julio de 1911 (artículo 15), antecedente inmediato de la Ley General Presupuestaria de 4 de enero de 1977 (artículo 44), en donde vuelve a quedar recogido el privilegio administrativo de la inembargabilidad ${ }^{26}$.

De toda la historia normativa del privilegio de la inembargabilidad el Tribunal Constitucional deriva en su sentencia dos tipos de consecuencias que resume en el último párrafo del citado Fundamento Jurídico 3. :

«... en primer lugar, que tanto la autotutela ejecutiva de la Administración local como la inembargabilidad de la Hacienda municipal surgieron históricamente no sólo en atención a las concepciones jurídicas entonces dominantes - la separación sin interferencias mutuas entre la Jurisdicción y la Administración, como corolario de la división de poderes-, sino también por exigencias derivadas del principio de legalidad administrativa como del de legalidad presupuestaria. En segundo término, que ya en este momento histórico se consideró que la inembargabilidad de los distintos elementos que integraban la Hacienda Pública constituía un límite al ejercicio de la función jurisdiccional de los Jueces y Tribunales de hacer ejecutar lo juzgado» ${ }^{27}$.

\section{LA DOCTRINA DE LA STC 166/1998}

Explicado históricamente el privilegio de inembargabilidad de los bienes públicos es necesario detenerse ahora, y con obligado carácter de brevedad, en la doctrina que sobre el mismo contiene esta reciente e importante Sentencia constitucional 166/1998, de la que fue ponente el magistrado Julio Diego González-Campos. Recordemos antes, con todo, y de forma muy resumida, los hechos que le sirven de base.

cioso del Estado, cuyo artículo 18 vuelve a recordar lo dispuesto en la Ley de 25 de junio de 1870. Más tarde, el trascendental Real Decreto de 16 de marzo de 1886 de reorganización del servicio contencioso del Estado advierte en su preámbulo que «los caudales del Tesoro no pueden ser embargados ni comprendidos en el procedimiento de apremio..». Esta doctrina se reitera en los Reales Decretos de 11 de junio de 1897 y 30 de abril de 1898, citados en el Fundamento jurídico comentado de la Sentencia 166/1998. Cfr. también los datos normativos que proporciona BETANCOR ROdRIGUEZ, "La evolución histórico-normativa de la cjecución de sentencias contencioso-administrativas (1845-1956)», Documentación Administrativa, 209, 1987, págs. 199 y ss.

${ }^{26}$ El Real Decreto Legislativo 1091/1988, de 23 de septiembre, aprobó el Texto Refundido de la Ley General Presupuestaria. En análogos términos el privilegio se encuentra recogido también, entre otras disposiciones, en la Ley del Patrimonio del Estado, Texto articulado aprobado por Decreto 1022/1964, de 15 de abril (art. 18), y en la Ley 39/1988, de 28 de diciembre, reguladora de las Haciendas Locales (art. 154).

27 ARIÑo hizo notar que el privilegio de la inembargabilidad se afirmó desde antiguo basado en un doble motivo: como consecuencia necesaria de la inalienabilidad de los bienes públicos y de la presunción de solvencia que en todo momento acompañaba al Fisco. En los tiempos de la Revolución Francesa, la justificación de tal privilegio se hará derivar de los principios de separación de poderes, de legalidad presupuestaria y de continuidad de los servicios públicos. «Inembargabilidad de fondos públicos», Revista de Derecho Privado, 1970, págs. 755-757. 
Por Sentencia del Juzgado de Primera Instancia n..$^{\circ} 1$ de Burgos se condenó al Ayuntamiento de aquella ciudad al pago de una cierta cantidad a una entidad mercantil privada. Requerido de pago el Ayuntamiento sin que lo satisficiera, y después de distintos avatares procesales, dicha entidad mercantil reiteró ante el Juzgado su petición de ejecución de la sentencia condenatoria, solicitando que, a este fin, se procediese al embargo de un determinado solar $\mathrm{y}$, alternativamente, a la congelación y retención de todas las cuentas bancarias del municipio. El Juzgado dictó providencia disponiendo el embargo de bienes patrimoniales del Ayuntamiento en cuantía suficiente a cubrir las cantidades a cuyo pago había sido condenado; dicho embargo se acordó por aplicación del artículo $80-10^{\circ}$ de la Ley Básica de Régimen Local (LBRL) interpretado a sensu contrario, ya que allí la inembargabilidad se predica exclusivamente de los bienes de dominio público y de los comunales. Confirmada en reposición dicha providencia e interpuesta apelación por el Ayuntamiento ante la Audiencia Provincial, ésta decidió plantear la cuestión de inconstitucionalidad de los apartados segundo y tercero del artículo 154 de la Ley 39/1988, de 28 de diciembre, reguladora de las Haciendas Locales (LHL), por entender que podrían vulnerar los artículos 24-1. ${ }^{\circ}, 117$ y 118 de la Constitución (CE) puesto que el monopolio jurisdiccional de ejecución de sentencias se vería obstaculizado caso de mantenerse la inembargabilidad de todos los bienes del Ayuntamiento demandado y no sólo la de los demaniales y comunales ${ }^{28}$.

En esta Sentencia 166/1998 comienza recordando el Tribunal Constitucional su antigua jurisprudencia, que ya nos es conocida, de que una resolución judicial firme de condena a la Administración no se convierte en un título directamente ejecutable, sino que el pago ha de llevarse a cabo a través de un procedimiento administrativo de ejecución del gasto. El problema, según el Alto Tribunal, está en saber si este procedimiento administrativo de ejecución del gasto

«es en verdad idóneo, en todo caso, para garantizar el cumplimiento de las Sentencias condenatorias de la Administración local. Y si se llegase a una respuesta negativa, sería preciso examinar, desde la perspectiva del art. 24.1 CE, si la prohibición de embargo que el art. 154.2 LHL establece con carácter general posee una justificación constitucional y, además, si es proporcionada y no excesiva» (F.J. 4. ${ }^{\circ}$ ).

\footnotetext{
${ }^{28} \mathrm{Al}$ momento del planteamiento de la cuestión de inconstitucionalidad los preceptos cuestionados del artículo 154 LHL disponían lo siguiente: «2. Los Tribunales, Jueces y autoridades administrativas nó podrán despachar mandamientos de ejecución ni dictar providencias de embargo contra los derechos, fondos, valores y bienes en general de la Hacienda Local ni exigir fianzas, depósitos y cauciones a las Entidades locales. 3. El cumplimiento de las resoluciones judiciales que determinen obligaciones a cargo de las Entidades Locales o de sus Organismos autónomos corresponderá exclusivamente a las mismas, sin perjuicio de las facultades de suspensión o inejecución de sentencias previstas en la Leyes».
} 
Pues bien, la Sentencia comentada se apresura a puntualizar que el régimen legal especial de ejecución forzosa establecido en el art. 154-2. ${ }^{\circ}$ LHL no es por sí mismo inconstitucional, ya que lo que debe determinarse es, antes que nada, si la inembargabilidad alli prevista responde a razonables finalidades de protección de valores, bienes o intereses constitucionalmente protegidos (F.J. $5^{\circ}$ ).

El Tribunal Constitucional, siguiendo también su jurisprudencia anterior, admite que, en ningún caso, el principio de legalidad presupuestaria puede justificar que la Administración retrase la ejecución del fallo condenatorio más allá del tiempo razonablemente necesario para obtener las correspondientes consignaciones presupuestarias, lo cual obliga a examinar si el procedimiento de pago previsto en el apartado $4 .^{\circ}$ del citado artículo 154 es idóneo para evitar que se produzca un indeseable retraso en el cumplimiento de las sentencias (F.J. $7^{\circ}{ }^{2}{ }^{29}$.

\section{La sentencia debe concluir que}

«el art. 154.4 LHL no impide que el ente local deudor persista en el incumplimiento de la Sentencia condenatoria y posponga o difiera el pago al particular, pese a que tanto éste como el órgano jurisdiccional hayan actuado con la debida diligencia legar posible para remover la obstaculización producida (STC 67/1984, fundamento jurídico $\left.2 .^{\circ}\right)$. De suerte que, agotada la eficacia del régimen general de pago del art. 154.4 LHL, caso de que no se satisfaga el derecho de crédito del particular, y, por tanto, se incumpla la resolución judicial condenatoria, se plantea el problema de la inembargabilidad que el art. 154.2 establece» (F.J. 8. ${ }^{\circ}$ ).

El Tribunal Constitucional se ve así directamente confrontado con la justificación de la inembargabilidad de los derechos, fondos, valores y bienes en general de la Hacienda local, prevista en el citado 154-2. ${ }^{\circ}$. No ve dificultad el Tribunal en afirmar la inembargabilidad de los derechos, fondos y valores, esto es, de los recursos financieros, de la Hacienda local en cuanto los considera «preordenados en los presupuestos de la Entidad a concretos fines de interés general». Su intangibilidad vendría, además, justificada por los principios de eficacia y de continuidad en la prestación de los servicios públicos.

Distinta es, sin embargo, según la Sentencia 166/1998, la situación de los bienes en general de la Hacienda local, pues para determinar en qué medida les alcanza el privilegio de la inembargabilidad ha de acudirse a

${ }^{29} \mathrm{El}$ artículo $154-4 .^{\circ}$ de la LHL dispone que «la Autoridad administrativa encargada de la ejecución acordará el pago en la forma y con los límites del respectivo presupuesto. Si para el pago fuere necesario un crédito extraordinario o un suplemento de crédito, deberá solicitarse del Pleno uno $u$ otro dentro de los tres meses siguientes al día de la notificación de la resolución judicial». 
la distinción tradicional entre bienes de dominio público y bienes patrimoniales, completándose la primera categoría con la de los bienes comunales.

Reconociendo el Tribunal «un cierto carácter mítico» a la mencionada distinción y subrayando, de otro lado, la falta de homogeneidad de la noción de dominio público, el criterio de la afectación del bien a un uso o a un servicio público le parece el determinante a la hora de distinguir aquél de los bienes patrimoniales. «Es la afectación del bien a un uso público o a la prestación de un servicio público - nos recuerda el Tribunal en su Sentencia-, entre otras finalidades constitucionalmente legítimas, lo que justifica su especial.protección por parte del Ordenamiento jurídico»; su inembargabilidad, por tanto, está justificada en atención a la función de satisfacción de necesidades colectivas primarias que cumplen, en el caso del llamado demanio natural, y a la eficacia de la actuación administrativa y a la continuidad en la prestación de los servicios públicos, en el caso de los bienes afectados a un servicio o a una función pública (F.J. 11. ${ }^{\circ}$ y $12 .{ }^{\circ}$ ).

Los bienes patrimoniales, en la medida que no reúnen las anteriores características, no gozan del privilegio de la inembargabilidad; de aquí que - nos señala la Sentencia - se vean excluidos de la protección reforzada del artículo $132-1 .^{\circ} \mathrm{CE}$. En ellos — se señala en el F.J. 12. - el interés general sólo está presente en atención a su titular, un ente público, pero no en cuanto a la actuación que a aquél le corresponde llevar a cabo. Es por ello por lo que los bienes patrimoniales son objeto del tráfico privado y responden del cumplimiento de las obligaciones contraídas por su titular (artículo 1911 CC). Por todo esto

«no está constitucionalmente justificado el excluir que los bienes pertenecientes al patrimonio de las Entidades locales, siempre que no estén materialmente afectados a un servicio público o a una función pública, respondan de las obligaciones contraídas por la Corporación local con los particulares y, en concreto, de las declaradas en una Sentencia judicial» (F.J. 13..$^{\circ}$ ).

De la lectura de esta Sentencia puede obtenerse, por lo demás, un cierto sentimiento de insatisfacción sobre el grado de elaboración actual, que dista mucho de ser acabada, de la teoría de los bienes públicos. La distinción que allí se opera entre bienes demaniales y bienes patrimoniales materialmente afectados a un uso o servicio público (F.J. 14. ${ }^{\circ}$ ) no dejará de plantear problemas de determinación conceptual ${ }^{30}$. En todo caso esta te-

${ }^{30} \mathrm{Cfr}$. la alusión a los patrimonios municipales del suelo, a los montes vecinales en mano común o a los bienes de notable valor histórico, artístico, arqueológico, científico, técnico o cultural en el 
mática nos llevaría muy lejos del objetivo de estas líneas y alargaría de forma innecesaria estas reflexiones, centradas, simplemente, como ya se ha dicho, en dar cuenta del hecho mismo del tratamiento directo del privilegio administrativo de la inembargabilidad por parte de nuestro Tribunal Constitucional ${ }^{31}$.

Sin embargo, y a modo de resumen final, quisiera, para terminar, destacar algunos puntos que podrían merecer alguna reflexión más detenida que la que se hace en estas páginas.

En primer lugar puede subrayarse el hecho de que el alcance del principio de legalidad presupuestaria experimenta una cierta relativización en la medida en que, como hemos visto, ha de ceder ante los retrasos injustificados en el procedimiento de pago previsto en el artículo $154-4 .^{\circ} \mathrm{LHL}$. Ello conlleva una, más bien modesta, flexibilización del privilegio de la inembargabilidad que, por lo demás, ha visto declarada su constitucionalidad con base en los citados principios de eficacia de la actuación administrativa y de continuidad en la prestación de los servicios públicos ${ }^{32}$.

F.J. 14. ${ }^{\circ}$ En la Exposición de Motivos de la reciente Ley 29/1998, de 13 de julio, reguladora de la Jurisdicción contencioso-administrativa, se alude a una «nueva regulación, completa y sistemática, del estatuto jurídico de los bienes públicos».

${ }^{31}$ En el F.J. $12 .^{\circ}$ de la Sentencia el Tribunal llega a la siguiente conclusión final:

«Que el régimen general de pago previsto en el artículo $154.4 \mathrm{LHL}$ no garantiza, por sí solo, que la Entidad local deudora cumpla con el mandato judicial, pudiendo posponer o diferir la ejecución de la Sentencia y quedando así insatisfecho el derecho de crédito del particular acreedor, por lo que la inembargabilidad establecida en el art. 154.2 LHL, en la medida en que se extiende a «los bienes en general de la Hacienda local» y comprende los bienes patrimoniales no afectados materialmente a un uso o servicio público, no puede considerarse razonable desde la perspectiva del derecho a la ejecución de las resoluciones judiciales firmes que el art. 24.1 CE reconoce y garantiza».

En consecuencia, la Sentencia declara la inconstitucionalidad y nulidad del inciso «y bienes en general» del art. 154.2 de la Ley 39/1988, de 28 de diciembre, reguladora de las Haciendas Locales, en la medida en que no excluye de la inembargabilidad a los bienes patrimoniales no afectados a un uso o servicio püblico.

${ }^{32}$ Cfr. Ballesteros Moffa, cit., págs. 18-19. La Exposición de Motivos de la nueva LJCA (VI-3.') indicó que no se ha pretendido eliminar la prerrogativa de la inembargabilidad de los bienes y derechos de la Hacienda Pública, «ya que dicha modificación no puede abordarse aisladamente en la Ley jurisdiccional, sino - en su caso- a través de una nueva regulación, completa y sistemática, del estatuto jurídico de los bienes públicos». No se comprende muy bien qué dificultades técnicas insuperables se hubiesen dado para que la LJCA no pudiese abordar (como ha hecho, p. e., el art. 170 de la $V_{w} G O$ alemana) el alcance del privilegio de la inembargabilidad, sobre todo si se tiene en cuenta, como ha observado certeramente GARCIA DE ENTERRIA, Curso, cit., II, pág. 644, que aquella se define precisamente como una prohibición de ejecución judicial. Por cierto que este mismo autor, a partir de la nueva dicción del artículo 106-1. ${ }^{\circ} \mathrm{LJCA}$ que ha previsto la existencia de un crédito, con la consideración de ampliable, para hacer frente a las sentencias de condena a la Administración a pago de cantidad líquida, ha propuesto la imaginativa solución de dirigir la ejecución forzosa precisamente sobre estos fondos, supuesto el título presupuestario explícito (cit., págs. 647-648). 
En segundo lugar, el privilegio de la inembargabilidad se extiende a los recursos financieros (derechos, fondos, valores) de la Administración local y, en general, de todas las Administraciones públicas, por entender que los mismos se hallan globalmente vinculados a fines de interés general. Por las razones a las que antes se ha aludido, no parece que pueda justificarse técnicamente esta extensión del privilegio por la misma naturaleza de los bienes sobre los que recae, no mencionados, por lo demás, como ya se ha apuntado, en la norma constitucional del $132-1 .^{\circ}$. De otro lado, esta especial naturaleza de los fondos públicos hace muy dificil que, en caso de embargo, se pudiesen ver negativamente afectadas la eficacia de la actuación administrativa o la prestación de los servicios públicos ${ }^{33}$. En todo caso, no parece que el hecho de la afectación o vinculación inmediata de determinadas partidas presupuestarias a concretas finalidades públicas pueda ser base suficiente para afirmar, sin más, la demanialidad del dinero público y, por consiguiente, su carácter inembargable.

Por último, debe advertirse de nuevo que la categoría utilizada por el Tribunal, a efectos de su inembargabilidad, de bienes patrimoniales afectados a un uso o servicio público, no dejará de plantear en la práctica, como ya he indicado, dificiles problemas de determinación, tanto más cuanto que, aunque ello no sea decisivo, es una categoría no expresamente prevista en el artículo 132 de la Constitución ${ }^{34}$. Es precisamente en este punto, como he señalado ya, donde se echa de menos, todavía hoy, una elaboración dogmática más afinada de la teoría de los bienes públicos. Y ello a pesar del gran debate doctrinal que sobre el criterio de determinación de la utilidad pública de los bienes se llevó a cabo durante largo tiempo en los principales Derechos europeos con resultados no definitivos. Debate, por cierto, que en gran parte se ahorró.la doctrina española en la medida que nuestro Derecho positivo hizo reposar dicha utilidad pública de los bienes sobre el criterio formal de la afectación como determinante de la demanialidad y sólo de la demanialidad; criterio formal que ahora, a la vista de la nueva categoría de bienes patrimoniales afectados a un uso o a un servicio público, ha de ser ineludiblemente revisado en su significado y alcance.

La introducción de esta nueva categoría de los bienes patrimoniales, que recuerda mucho a la noción italiana de patrimonio indisponibile, va a

${ }^{33}$ En último término, en los supuestos más graves, habria que tener presente también la cautela prevista en el artículo 106-4..$^{\circ}$ LJCA. Una posición crítica sobre la misma en GARCLA DE ENTERRIA, Curso, II, cit., pág. 648.

${ }^{34}$ Cfr., últimamente y por todos, el completo comentario de F. SÁINZ MORENo al artículo 132 de la Constitución en Comentarios a la Constitución española de 1978, dirigidos por O. Alzaga, tomo X, 2. ${ }^{a}$ edición, Ed. de Derecho Reunidas, Madrid, 1998, págs. 183 y ss. y bibliografia allí citada. 
exigir, en efecto, una nueva reflexión sobre el papel que la técnica de la afectación cumple, en todas sus formas, respecto de los bienes públicos y sobre los instrumentos de determinación de los bienes integrantes de la nueva categoría. En cualquier caso, toda esta problemática nos vuelve a poner de manifiesto la innegable existencia de una gradación de la utilidad pública de los bienes que corrobora, por si ello fuese necesario, lo acertado de la idea de la escala duguitiana, y subraya la necesidad de la existencia de regímenes jurídicos diferenciados.

No pueden ir más allá estas reflexiones so pena de desbordar el marco que me he fijado en este comentario. Resta, en todo caso, por señalar que el legislador ha tenido inmediatamente en cuenta la doctrina contenida en la Sentencia 166/1998 y ha procedido en la reciente Ley 50/1998, de 30 de diciembre, de Medidas Fiscales, Administrativas y del Orden Social (artículo 57-2..$^{\circ}$, a dar una nueva redacción al apartado $2 .^{\circ}$ del artículo $154 \mathrm{LHL}$, que queda como sigue:

«Los Tribunales, Jueces y Autoridades administrativas no podrán despachar mandamientos de ejecución ni dictar providencias de embargo contra los derechos, fondos, valores y bienes de la Hacienda Local ni exigir fianzas, depósitos y cauciones a las Entidades Locales, excepto cuando se trate de bienes patrimoniales no afectados a un uso o servicio público.»

Con independencia que hubiese sido deseable una modificación del resto de la normativa sobre el privilegio de inembargabilidad, lo cierto es que, como ha sido ya oportunamente puesto de manifiesto ${ }^{35}$, ha de adjudicarse a la Sentencia 166/1998 un alcance más general, aplicando directamente su doctrina a aquella normativa. La aplicación de las leyes según. los preceptos y principios constitucionales, conforme a la interpretación de los mismos por el Tribunal Constitucional (artículo 5-1. ${ }^{\circ}$ LOPJ), así lo exige ${ }^{36}$.

\footnotetext{
35 García de Enterria, Curso, II, cit., pág. 646. Martin Rebollo (ed.), Leyes administrativas, ed. 1998, Aranzadi, Pamplona, 1998, págs. 1203-1204.

${ }^{36}$ En pruebas el presente trabajo ha aparecido el interesante estudio de Colom Piazuelo, «Los bienes públicos y su estatuto jurídico: reflexiones en torno a la inconstitucionalidad del principio de inembargabilidad de los bienes públicos declarada por la STC 166/1998, de 15 julio», Repertorio Aranzadi del Tribunal Constitucional, núm. 19, enero 1999, págs. 17-50, que no he podido tener en cuenta en la redacción de estas líneas por lo que he de limitarme aquí a su mera cita.
} 
